\title{
MEASURING AND MONITORING JOB READINESS ${ }^{1}$
}

\author{
William C. Wedley, Sameer Sharma, Suzanne Klinga and William J. Scott \\ Simon Fraser University, Burnaby, B.C., Canada, V5A 1S6, wedley@sfu.ca \\ IBM Canada, Vancouver, B. C., ssharma@ca.ibm.com \\ Kwantlen University College, Surrey, B.C., sklinga@helix.net \\ Richmond Youth Services Agency, Richmond, B.C., Canada, wjscott@istar.ca
}

\begin{abstract}
For social aid and placement agencies, measuring the readiness of unemployed people to assume and hold a job is important for effective counseling, assignment of clients to programs, and monitoring of training outcomes. Traditionally, the assessment of individuals has been done in a cursory or intuitive fashion. Through the Analytic Hierarchy Process, the importance of the many aspects of job readiness can be ascertained. Then by way of a user-friendly decision support system, the AHP results are used to both measure and monitor progress along job readiness dimensions. User response to the new tool is very positive.
\end{abstract}

\section{Introduction}

In a fast changing economy, businesses innovate and alter their employment mix. Usually there is a residual of people who want work but do not have the requisite skills to enter the job market. They may be people who did not update their job skills, they may not have acquired the requisite skills before they left high school, or they may have had personal barriers that make it difficult for them to proactively search for a job. The one thing such people have in common is that they are not "job ready" -- they do not have the wide range of skills and personal qualities that are sought by employers for basic level jobs.

In chronic cases, these people end up on welfare or other social problems such as unemployment insurance. When they get a job, they frequently become a turnover statistic when their employer realizes that their personal problems or their lack of skill is a hindrance on the job. Being on social support programs or achieving substandard performance, these people are a burden to the economy. Moreover, their personal burden is heavy, because continual rejection in the job market leads to loss of self-esteem.

One solution undertaken by social agencies in the province of British Columbia, Canada is to undertake training programs and other interventions that upgrade skills and overcome the particular deficiencies of the client. A training counselor/consultant from a government social agency will interview the unemployed person (the client) to ascertain specific weaknesses. Then the client will be referred to training programs run by private or public agencies but primarily funded by the government. These training agencies are called contractors.

Although the training consultants are experienced, their evaluation of clients tends to be holistic and intuitive. Sometimes they end up referring clients to programs for which the clients are inappropriate. The contractors then complain. In reverse, the training consultants claim that contractors are not accountable, since there is no way to determine whether training leads to improved client skills.

In order to resolve such problems, a research team began to investigate methods for isolating the various factors that determine basic job readiness and the methods that could be used to measure it. The team soon chose the Analytic Hierarchy Process (AHP) as a likely method for measuring and monitoring job readiness. This paper describes the process the team used AHP to measure job readiness and then how

\footnotetext{
${ }^{1}$ Acknowledgement: The authors thank the Natural Sciences and Engineering Research Council, Canada and the Richmond Youth Services Agency for financial support that helped complete this project.
} 
the AHP results were integrated into a user-friendly decision support system for implementation. Responses to the new tool are reported for both training consultants and contractors.

\section{Dimensions of Job Readiness}

Around the world, the term "employability skills" is generally used to describe the range of basic skills and personal qualities that are relevant for effective job performance. They include not only the literary (reading, writing, speaking) and numerical skills normally associated with formal education, but also the behaviours of adaptability, flexibility, reasoning, and consistency that are important in the workplace. A search of the literature revealed that although a lot has been done in the area of describing employability skills (McLaughlin, 1992), little work has been done in the area of measuring and monitoring it.

Starting from the existing literature base, a focus group composed of training consultants and contractors worked with two of the project coordinators to formulate a hierarchy of relevant job dimensions. They identified four main factors (Core Skill, Teamwork, Personal Management and Environmental factors) which were further broken down in criteria and sub-criteria.

Figure I depicts the hierarchical structure of the factors, criteria and sub-criteria, along with the local weights from using AHP's absolute mode. For each of the bottom level sub-criteria in Figure 1, the expert group specified 5 benchmarks along the continuum of job readiness for that dimension. For example, "Read" under "Communicate" in "Core Skill Factors" had the following five benchmarks:

5. Ability to read at a Grade 10 equivalency level (.489)

4. Ability to read at a Grade 8 equivalency level (.232)

3. Ability to read at a Grade 6 equivalency level (.192)

2. Ability to read at a Grade 4 equivalency level (.050)

1. Unable to read (.036)

In each case, the top position on the continuum (i. e. level 5) was described as the necessary proficiency level to be job ready for an entry-level position requiring minimal skills. In other words, level 5 is the basic proficiency level for a "job ready" person and all other levels are below that standard. Thus, a person with Grade 6 reading ability can be interpreted as being .192/:489 or 39\% proficient. This does not necessarily mean that a person with a Grade 6 reading ability cannot get a job, but it does mean that a person with such skills would be considered to be below standard on that dimension. A person who achieves level 5 on all dimensions would be considered to be $100 \%$ job ready.

The priorities for the main factors, criteria and sub-criteria were generated using the concepts of linking pin AHP (Schoner, Wedley and Choo, 1993). For all paired comparisons between factors, criteria or subcriteria, focus group members used a level 5 person as their referent or link between clusters. This means that the priorities in Figure 1 represent the relative importance of the factor, criteria, or sub-criteria possessed by a level 5 person. Therefore, aggregation to get.global weights should result in the level 5 benchmark receiving $100 \%$ of the composite weights from above. This can be accomplished by renormalizing the benchmarks so that level 5 has a value of unity and then multiplying by the product of all higher level local weights.

For the "Read" dimension, the global weights are calculated as follows:

Level 5. Grade 10 reading equivalency (.489)

Level 4 . Grade 8 reading equivalency (.232)

Level 3. Grade 6 reading equivalency (.192)

Level 2. Grade 4 reading equivalency $(.050)$

Level 1. Unable to read (.036)

Renormalized and Multiplied by Upper LW

$.489 / .489=1.0 \times .208 \times .482 \times .157=.0157$

$.232 / .489=.474 \times .208 \times .482 \times .157=.0075$

$.192 / .489=.393 \times .208 \times .482 \times .157=.0062$

$.050 / .489=.102 \times .208 \times .482 \times .157=.0016$

$.036 / .489=.007 \times .208 \times .482 \times .157=.0012$ 
GOAT: Measure Job Readiness
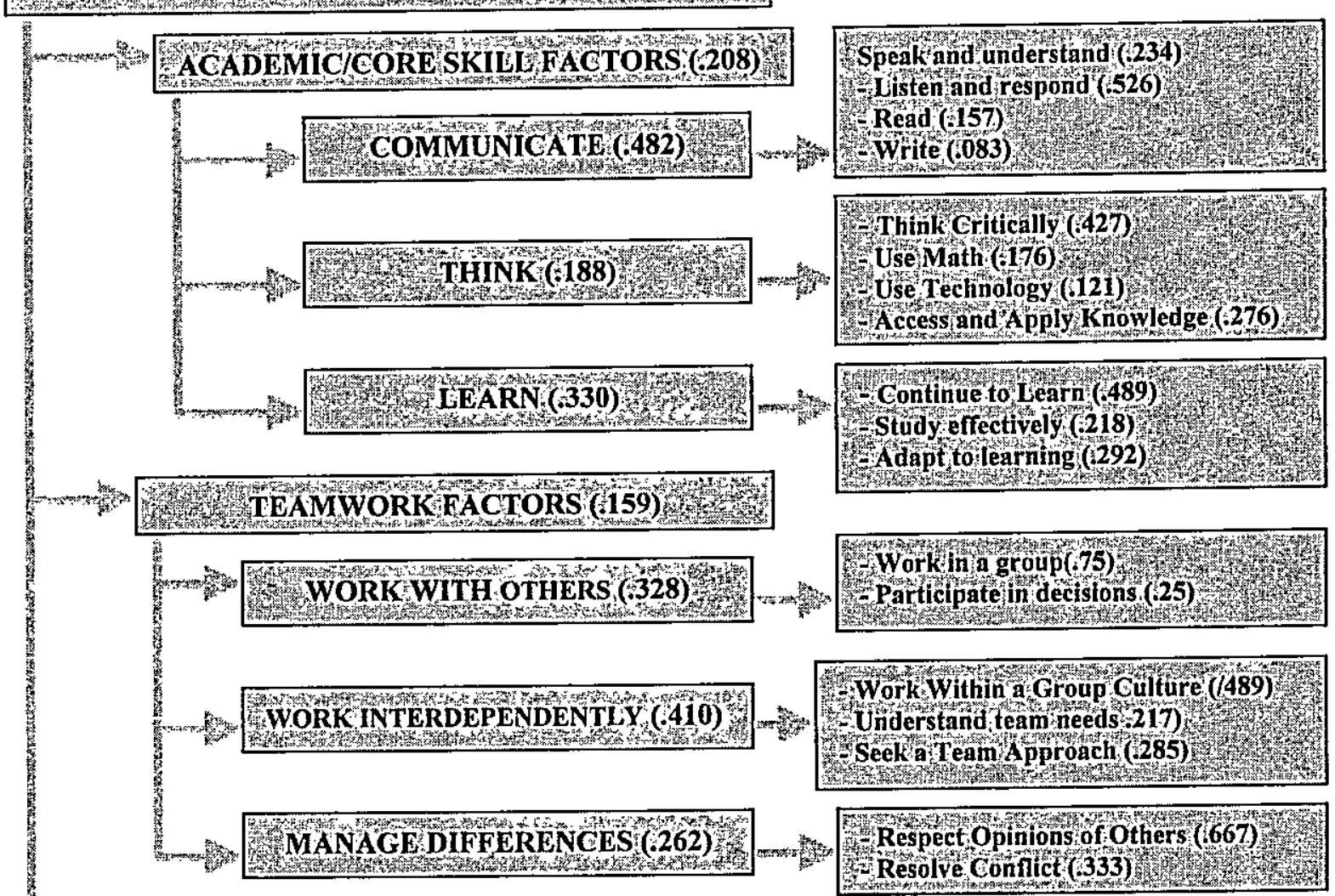

W. Workin a group (i75)

Participatein decisions. (25)

6ring

-Work Within a Group Culture (489)

Understand team needs 217 )

Seek a Team Approach (285)

15y.

Respect Opinions of Others ( 667$)$

Resolve Confict ( $(333)$

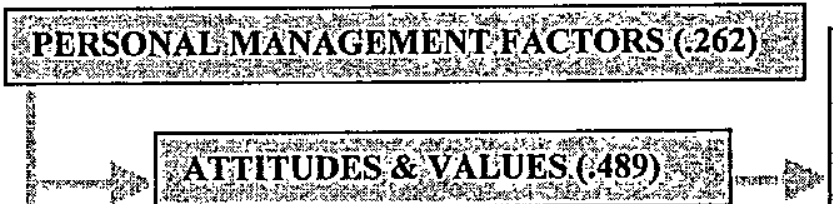

Self awareness $(098)$

Self esteem (175):

Work ethics ( 304)

Positive Outlóok (227)

Initintive(6196)

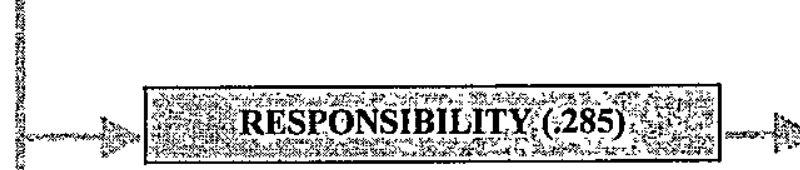

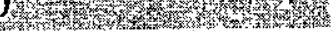

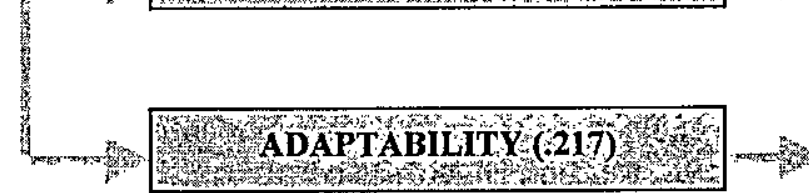

- Receptive to change (.493)

- Respect for diversity (196)

- Apply options (311)

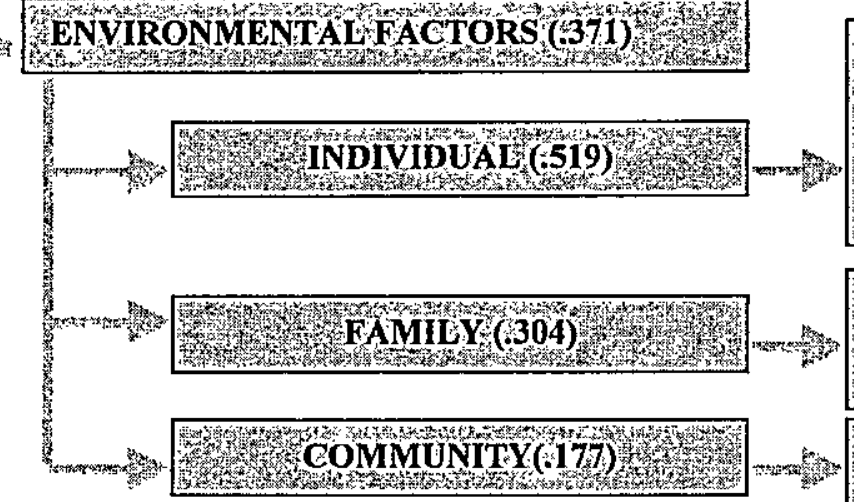

Set \& work towards real goals $(275)$

Manage resources (289)

A ccountable for consequences (436)

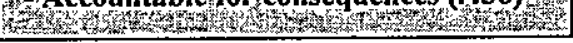

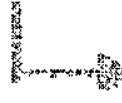

ENVIRONMENTAL FACTORS $(4371)$ \%

Personal History (063)

Physical Health (236)

Mental Health $($ 148)

Emotional Health (149)

Adequate food cloths shelter $(603)$,

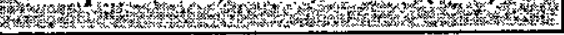

(1)

Family stipport (685)

Family Health (288)

Fanily Responsibilities (227)

Social Resources ( 286$)$

Infrastructure Resources $(714)$

Figure 1: Hierarchy of Main Factors, Criteria, Sub-criteria and Local Weights 
In line with conventional AHP practice, this renormalization assures that a person who scores at level 5 on all sub-criteria receives. a composite priority equal to one. However, the project team felt that implementation would be enhanced if the renormalized priorities were expressed as a percentage, where a $100 \%$ job ready person on all sub-criteria would receive a score of 100 . Accordingly, we renormalized again by multiplying by 100 . Now, a person who scores job ready on all criteria (i. e. level 5) receives a score of 100 and a person less than job. ready receives a score proportionately less than 100 . In other words, a level 5 person in reading ability would receive 1.57 percentage points towards being job ready, whereas another person at Grade 6 reading equivalency would receive just .62 percentage points.

In addition to displaying overall job readiness as a percentage of 100 , the project team expressed performance on each criterion as a percentage of the best attainable achievement on that criterion. This disaggregated perśpective enables the user to look at the particular dimensions of job readiness.

\section{A Job Readiness Decision Support System}

Having developed a method for measuring job readiness, the next step was to devise a mechanism to implement it. The project team realized that any implementation would have to be transparent and easy to use. Since training consultants feel that they are already overburdened, any new process would have to take very little or no extra time. The process would have to be able to allow input of both client and counselor information, and would have to be able to save, record, and display measurements of the same client at different stages in the training process, particularly in graphical form. It should also be flexible enough to allow updating and revision of AHP weights for other applications or for changed conditions. To achieve this, the project team chose a computer-based environment.

Sharma (1999) developed the computer interface for the project. An analysis of different computer-based information systems soon revealed that the job readiness situation could be characterized in a decision support system (Turban and Aronson, 1998). Determining job readiness entails semi-structured methods, sequential decisions, data management, model management, interactive use, an AHP knowledge base, and managerial discretion. In such cases, computer procedures in the form of a decision support system (DSS) can be designed to facilitate the decision making process.

A prototyping approach was adopted for the development of the Job Readiness DSS (Bernstein, 1985). This involved identifying system requirements, developing a model, testing the prototype, redefining an improved model, testing, and integrating with existing systems. Besides a short development time, this approach allowed user input and feedback, improved understanding of the system, and low cost.

In selecting the software design platform, the six classifications proposed by Holsapple and Whinston (1996) were considered. The simplicity of a spreadsheet design was contemplated, but soon discarded because of its disadvantages of flat file structures, data redundancy, and poor interface design. Instead, a database approach was selected for its ability to handle abundant data, report generation and queries. In the end, the relational database facility, Microsoft Access, was selected as the software platform. Not only does it offer efficient queries, but it also has the capability to provide menus and graphic displays.

Programming was undertaken for 8 relational databases, two query procedures, and 21 different forms. The databases contain client and counselor information, the readiness scores of clients, and the AHP benchmark information. The two query procedures determine the AHP generated scores from the databases. The forms determine the user interface for inputting, displaying and retrieving information.

\section{Features of the DSS Output}

The main menu of the Job Readiness DSS simply directs the user to edit existing information, enter new information, or view a client record. The edit submenu allows alterations of readiness scores, client information or counselor information. Ordinarily, the user would be entering new information on clients, scores and counselors or viewing client records. 

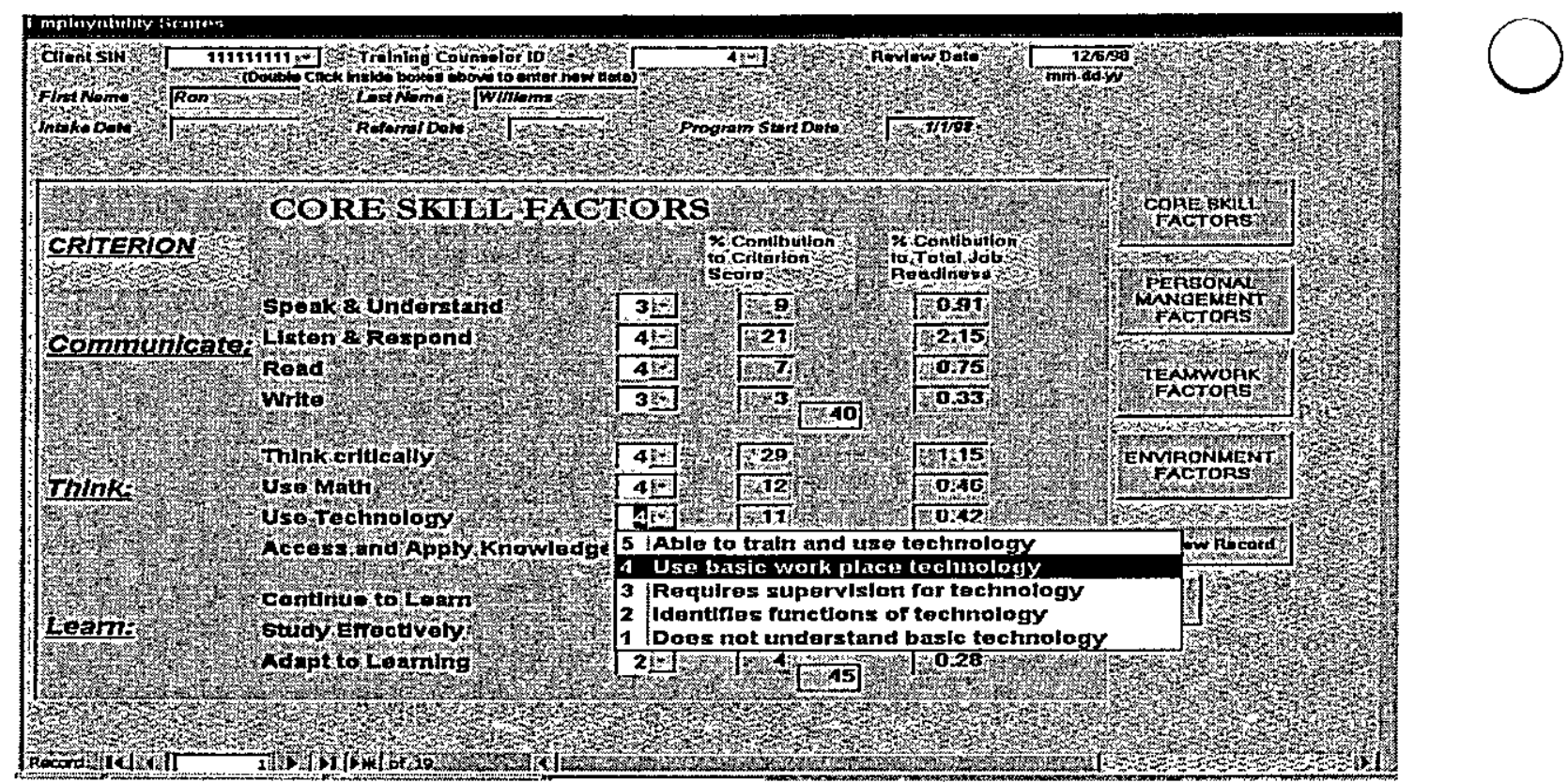

Figure 2: Drop Down Menu for Selecting Benchmarks and Entering Client Scores

Figure 2 illustrates the screen for entering Core Skill Factors. As shown, simply simply clicking on the appropriate descriptor in a drop-down menu makes entries. Upon selection, the AHP \% contribution to the criterion score and the Total Job Readiness is immediately displayed. Notice that the client displayed in Figure 2 has level 4 reading ability that is worth .75 percentage points towards overall job readiness. The person is $40 \%$ proficient in communication and $45 \%$ in learning ability. By clicking on the buttons of the right side of the screen, similar screens are available for the other main factors.

Figure 3 displays the progress of a client in graphic form. Screens are also available for displaying the same information in tabular form. By clicking on the command buttons at the right of the screen, users can display more detailed breakdowns according to any of the four main factors.

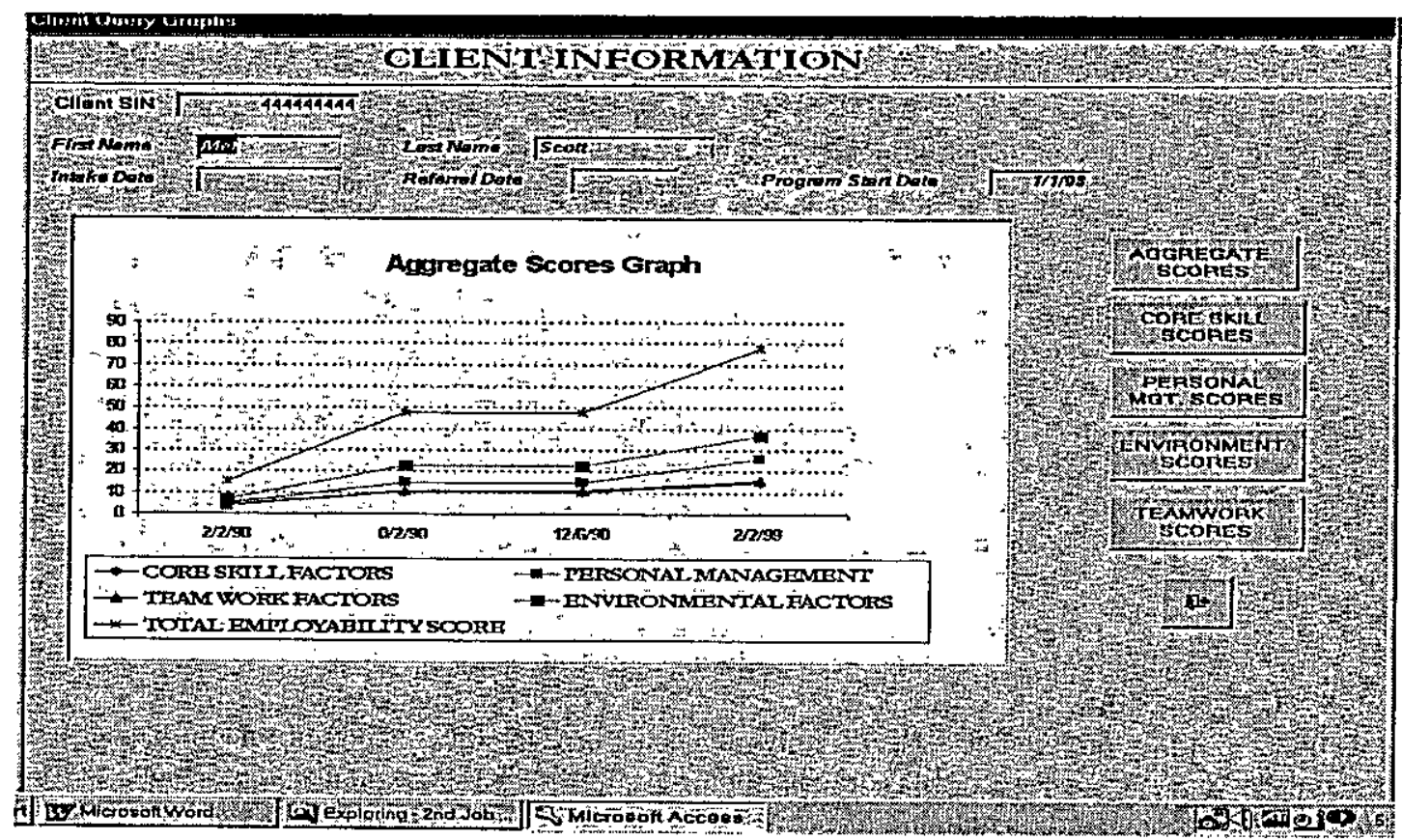

Figure 3: Graphic Display for Showing the Progress of a Client 


\section{User Reactions}

To evaluate the efficacy of the Job Readiness DSS, 5 members of the focus group and 4 non-focus group members answered a questionnaire regarding the present vs. the proposed system (Sharma, 1999). In general, both qualitative and quantitative analyses revealed positive responses to the proposed system. On a ten point Likert scale, the proposed DSS method was judged to be better for evaluating.clients (average score of 7.6 vs. $4.7, p<.02)$ and for assigning clients to training programs ( 7.9 vs. $4.3, p<.001)$. Moreover, the DSS scored high on ability to determine the effectiveness of training programs (8.1), easy data entry (8.2) and user friendliness for giving feedback (8.7). However, the improvements come at a cost. Respondents felt that their evaluation workload would increase by about 20 percent.

Confirming evidence came from AHP questions comparing the present to the proposed DSS in their ability to (1) evaluate clients strengths and weaknesses, (2) place clients in improvement programs (3) monitor and evaluate client progress, (4) give clients feedback and (5) give financial sponsors feedback. On all five criteria, the DSS approach was judged to be at least 2.7 times better $(p<.0025)$. With such dominance, AHP aggregation to get a composite score is unnecessary.

To make sure these favorable results are not attributable to the optimism of the focus group that formulated the AHP portion of the project, the questionnaires were analyzed for differences between focus group and non-focus group respondents. Whether for the present or the proposed system, there were no pattern or statistical difference between the two groups. In a like manner, an analysis was undertaken comparing responses from contractor respondents and training consultant respondents. Except for the training consultants saying that the DSS would provide greater ability to give feedback to financial sponsors, there were no statistically significant differences.

\section{Conclusion}

Present methods for assessing the job readiness of unemployed people and the assignment of them to improvement programs is done in a cursory and intuitive fashion. As shown in this paper, a group of experts can work with the existing literature, AHP, and their experience to devise a measurement mechanism. Such a mechanism, however, will be ineffective if it cannot be implemented in a userfriendly manner. This paper goes on to show how the AHP results can be merged with the relational database and interactive facilities of Microsoft Access so as to become a decision support system.

Steps are currently being undertaken to introduce the Job Readiness DSS under further experimental conditions. Given the positive response to date, the integration of AHP within a DSS framework holds out considerable promise to solve the highly subjective problem of measuring job readiness.

\section{References}

Bernstein, A. (1985). "Shortcut to System Design". Business Computer Systems. 4, 6, 70-76.

Holsapple, C.W., and Whinston A.B. (1996). Decision Support Systems: A Knowledge-based Approach. Minneapolis/St. Paul: West Publishing Company.

McLaughlin, M. M (1992). "Employability skills profile: what are employers looking for?" Ottawa : The Conference Board of Canada.

Schoner, B., Wedley, W. C. and Choo, E. U. (1993), "A unified approach to AHP with linking pins," European Journal of Operations Research, 64, 384-392.

Sharma, Sameer, (1999) Development of a Systematic Approach to Measure and Track Employability, MBA Research Project, Simon Fraser University.

Turban E. and Aronson J. (1998). Decision Support Systems and Intelligent Systems. Prentice Hall, New Jersey. 